\title{
Causes and consequences of dieting and anorexia
}

\author{
B Y ANDREW J. HILL \\ Academic Unit of Psychiatry, Leeds University, 15 Hyde Terrace, Leeds LS2 9LT
}

Dieting is the most common form of potential undernutrition in Britain. Recent findings show $12 \%$ of women in the UK between the ages of 16 and 64 years to be currently dieting, with nearly two-thirds consuming less than $6.3 \mathrm{MJ} / \mathrm{d}$ (Gregory et al. 1990). But if one in every eight adult women are currently dieting, a far greater proportion admit to a past history of dieting. Studies indicate that up to $70 \%$ of girls by late adolescence have already engaged in dieting behaviour (Hill et al. 1992). For women, dieting has come to represent the 'normal' eating style (Herman \& Polivy, 1991). Practised at some time by the majority, it encompasses a range of strategies. These, at their most basic, include avoiding eating for periods of time, the attempted avoidance of certain types of foods and an overall restriction of the amount of food eaten.

In contrast to the ubiquity of dieting, clinical eating disorders are relatively rare. Current estimates indicate that about one in every 150-200 girls aged between 15 and 18 years suffer from anorexia nervosa. These estimates are higher in the independent sector of education and in girls from higher social class backgrounds. Bulimia nervosa is more common and affects about $1-2 \%$ of women between the ages of 18 and 25 years. There has been a lot of conjecture about whether eating disorders are on the increase. Rising public and clinical awareness have almost certainly promoted their presentation and detection. However, the current information about anorexia nervosa, together with the fact that bulimia nervosa was first clinically described in 1979, argues that they are certainly not in decline. Moreover, it is widely agreed that the number of sub-clinical eating-disordered individuals is now vast, and that the cases identified and treated are only the tip of the iceberg of eating pathology.

But what about the connection between dieting and eating disorders? The lay person's view of anorexia nervosa is one of dieting gone wild. This wilful refusal to eat, leading to extreme emaciation, is a circumstance which many, particularly men, find mystifying and beyond their own life experience. The picture is one of dieting preceding anorexia, and of intensified dieting sustaining the illness. But even if this is accurate, is the relationship between dieting and anorexia merely coincidental or in some way causal? The argument presented here is that there are sufficient common themes in the origins and repercussions of dieting and eating disorders to imply causality. An important consequence is that changes in the promotion and perceived acceptability of dieting will result in a change in the levels of eating pathology.

\section{THE ORIGINS OF DIETING}

Dieting means many things to many people. To those trained in nutrition it is a fundamental process which has the potential to achieve significant and sustainable weight loss for obese individuals. Outside the clinical world it has become a buzz-word for aspiring to a socially-set physical agenda by means of interfering with the food supply. In other words, dieting can be both a valid clinical procedure and a strategy for cosmetic weight change. Three issues will be focused on. 
Table 1. A comparison of the present and the desired body weights of two groups of women (adapted from Fairburn \& Cooper, 1984)

(The percentage of each group whose present and desired weights are within each body.weight range (expressed as a percentage of the matched population mean weight; \% MPMW) and the mean and standard deviation for present and desired weights (\% MPMW) of each group)

\begin{tabular}{|c|c|c|c|c|}
\hline \multirow[b]{2}{*}{$\begin{array}{c}\text { Body wt } \\
\text { range } \\
\text { (\% MPMW) }\end{array}$} & \multicolumn{2}{|c|}{ Present wt } & \multicolumn{2}{|c|}{ Desired wt } \\
\hline & $\begin{array}{c}\text { Clinical sample } \\
(\text { (n 35) } \\
(\%)\end{array}$ & $\begin{array}{c}\text { Community sample } \\
(\text { ( } 369) \\
(\%)\end{array}$ & $\begin{array}{c}\text { Clinical sample } \\
(n 35) \\
(\%)\end{array}$ & $\begin{array}{l}\text { Community sample } \\
\qquad \begin{array}{c}(n 369) \\
(\%)\end{array}\end{array}$ \\
\hline$<85$ & $5 \cdot 7$ & $7 \cdot 4$ & $22 \cdot 9$ & $17 \cdot 9$ \\
\hline $86-100$ & $65 \cdot 7$ & $52 \cdot 3$ & $71 \cdot 4$ & $71 \cdot 5$ \\
\hline $101-115$ & $22 \cdot 9$ & $33 \cdot 7$ & $5 \cdot 7$ & $10-5$ \\
\hline$>115$ & $5 \cdot 7$ & 6.6 & 0 & 0 \\
\hline \multicolumn{5}{|c|}{ Body wt (\% MPMW) } \\
\hline Mean & $97 \cdot 3$ & $98 \cdot 0$ & $89 \cdot 4$ & $91 \cdot 5$ \\
\hline $\mathrm{SD}$ & $10 \cdot 3$ & $10 \cdot 3$ & $6 \cdot 5$ & $6 \cdot 3$ \\
\hline
\end{tabular}

First, it is apparent that dieting is not reserved for the truly overweight. While it may be more common in heavier people, dieting is practised by people in all weight categories. The desire to be thinner and the experience of feeling fat is part of the lives of an overwhelming number of women. Even women who fall comfortably within the medically-set limits for normal weight desire further weight loss. In general, and in women in particular, self-defined upper limits of weight acceptability are profoundly thinner than those officially advised. Take, for example, the participants in a study by Fairburn \& Cooper (1984). A clinical group of thirty-five women were compared with a 'community sample' of 369 women in terms of their present and desired weight (Table 1 ). Both groups were on average just below the mean of their matched-population weight. While similar in weight, they also shared a desire to be even thinner. Only $6 \%$ of the clinical group and $11 \%$ of the comparison group put their desired weight at above the population mean. Looked at another way, nearly $90 \%$ of these women desired to weigh less than the population mean. This outcome is of interest not because the clinical sample had an eating disorder (bulimia nervosa), but because their desire to be thinner was statistically inseparable from that of the normal control group of women. Moreover, their collective aspiration was incompatible both with their current population mean weight and the trends towards increasing obesity (Garrow, 1991).

If a desire for thinness is strong in adult women of normal weight, then it is also readily apparent in adolescence. In a recent study of London schoolchildren aged 11-18 years, $59 \%$ of the girls said they wanted to lose weight (Wardle \& Marsland, 1990). As with adults, body shape perception and satisfaction was at odds with their actual weight. Nearly $50 \%$ of the average-weight girls reported feeling fat. Nor are these patterns limited to adolescence. In a study of 9 year olds, over one-third of the average-weight girls reported wanting to be thinner (A. J. Hill, E. Jones and J. Stack, unpublished results). Dissatisfaction with weight and shape, therefore, is prominent from childhood through to adulthood and is only loosely based on actual weight.

The second issue relates to why these levels of body weight dissatisfaction exist. Dieting occupies a prominent place in the minds and lives of women because they are 
faced with two stereotypes: attracted by the lauded stereotype of slimness and repelled by the stigmatized stereotype of fatness. Dieting is the avenue which links the two, enabling a person to believe that it is possible to move away from one and closer to the other. Thinness embodies much of what women are believed to strive for. Thinness is delicate, feminine and the aesthetic ideal (Rodin et al. 1985). Thinness is equated with beauty, and beauty with success. Indeed, positive discrimination operates for slim attractive people in many social and work situations. Fat people, on the other hand, have a variety of negative personality characteristics attributed to them (De Jong \& Kleck, 1986). They are viewed by many, including doctors, as lonely, weak-willed and less intelligent than lean people. Fatness is characterized as a self-induced condition, caused by self-indulgence, gluttony or laziness. Moreover, fat people are actively discriminated against in a variety of social and employment circumstances.

In addition to these long-standing attributions of slimness and overweight, considerations of health have further coloured our perception of weight. Obesity has significant associations with ill-health (Garrow, 1991), and has become a primary issue in the British Government's targets for improved health. While profound overweight has clear links with morbidity, more mild degrees of overweight have at best only correlative associations with impaired health. Whether science has been poor at accurately presenting the health implications of overweight or the audience poor at personally evaluating and applying this information, weight has become a lay measure of health status. Overweight implies poor health and shortened life expectancy; thinness (i.e. underweight) is healthy. Feeling in less than perfect health can easily be remedied by losing a few pounds. Even cosmetic weight loss is believed to improve health.

The last issue concerns the nature of dieting itself. Dieting is the epitome of self-medication. Excess weight (or a less than desirably shaped part of the body) is self-diagnosed and a treatment course followed. No doctor's prescription is necessary as dieting is essentially over-the-counter medication. Its ease of availability is mirrored by its apparent inexpensiveness (buying less food) and the little physical effort expended in its pursuit (unlike exercising to lose weight). Furthermore, for the reasons mentioned previously, it is socially acceptable, being a sign of taking care of yourself. Critically, it is endorsed and promoted in many guises by the popular media and by industry. In its ease of access and its variety, dieting is almost impossible to resist. No matter what weight you are, for no discrimination is made in marketing the product, feeling fat can be assuaged by dieting.

\section{ORIGINS OF ANOREXIA NERYOSA}

There have been many theories proposed to account for the origins of anorexia nervosa. They reflect the different conceptual backgrounds of their proposers and the scientific climate dominating at the time of their proposal. Hsu (1983) has outlined six main theories and comments that while there is a degree of overlap, their main thrust and conceptualization are quite distinct. Briefly they are outlined below:

1. the social-cultural theory argues that the pressures on women in Western society to conform to a slim body shape are responsible for anorexia nervosa. However, what it fails to account for is why only a small proportion of women exposed to such pressures develop the illness;

2. family pathology theory points to the pattern of family interaction as responsible for 
the disorder. While this is a long-standing view, empirical support is far from overwhelming;

3. individual psychodynamic theory focuses on the individual's struggle for a selfrespecting identity. Although the approach has therapeutic utility it is difficult to appraise empirically;

4. the developmental psychobiological theory centres on the need to stop the maturational changes of puberty through starvation and so avoid the turmoil of growing up; 5. primary hypothalamic dysfunction theory proposes a biological disorder of unknown origin as responsible for the illness. Early onset of amenorrhoea and incomplete recovery of hypothalamic function despite weight gain is cited as supportive evidence;

6. atypical affective disorder has been used to argue that anorexia nervosa is no more than a variant of affective disorder or depression. This continues to be debated but has in the main been rejected.

These six theories all have utility in explaining the character and presentation (and so determining the therapeutic approach) of a significant number of cases of anorexia nervosa. And yet it seems unlikely that any single theory will be adequate to explain the aetiology of all cases. Rather, what these theories have identified are features of the complex chain of events which interact to precipitate the illness (Hsu, 1983). They range from the social and cultural climate, to biology and to individual construing of significant events. In many ways, anorexia nervosa represents a final clinical pathway which can be reached by a variety of routes.

One response to the complexity of the origins of this serious disorder has been to construct multi-dimensional approaches to aetiology (Levine, 1987). This integration of information has enabled the conceptual separation of factors which correspond to three categories: predispositions, precipitators and perpetuators. Broadly speaking, sociocultural, biogenetic, familial and personality variables are predispositions, and a variety of specific or anticipated events, precipitators. What is mobilized is a decision to diet. Common to all these conceptual models is the pivotal role dieting has in the evolution of anorexia. Moreover, the consequences of dieting, many of them direct products of the physiological and psychological effects of starvation, are important perpetuators of the illness, and serve to intensify dieting and so weight loss.

Before going on to consider these consequences in more detail, one point is worth briefly revisiting. If pre-disorder dieting is almost mandatory for the development of anorexia nervosa, why don't all dieters develop anorexia nervosa? This question of causality is difficult to address. There is no doubt that during adolescence dieting is a major risk factor for the later development of an eating disorder (Patton et al. 1990). The question is, what protects some adolescent girls and makes others vulnerable? Mapping out variables which predispose, precipitate and perpetuate eating disorders, represents an attempt to achieve this knowledge.

\section{THE CONSEQUENCES OF DIETING AND ANOREXIA}

Recent accounts for the main clinical features of eating disorders argue that most are secondary to the patients' overvalued ideas concerning their shape and weight (Fairburn \& Cooper, 1989). These secondary features include intensified and extreme dieting, self-induced vomiting, preoccupation with shape and weight, as well as binge-eating. Furthermore, a whole range of other features of anorexia nervosa are a product of 
starvation, either through the physiological consequences of malnutrition or the psychological effort in achieving and maintaining this state. These include cognitive changes, altered behaviour and changes in emotional state. An important question is whether any of these changes are detectable in people who are dieting. If this is found to be the case then it would substantiate the links between dieting and anorexia. A number of issues will be examined.

One of the major perceived barriers to effective weight loss for dieters is the much publicized alteration in metabolic rate. In an authoritative review, Prentice et al. (1991) concluded that although there is a suppression of metabolic rate whilst dieting, the extent of this fall may be smaller than popularly believed and that metabolic rate soon realigns itself to the new body size. In contrast, the physiological, metabolic and endocrine disturbances in anorexia nervosa are profound (Pirke \& Ploog, 1986). The common link between these changes is that they all probably result from the alteration in eating behaviour. In other words, these biological consequences are adaptations to a major shift in the food supply. Only in exceptional cases (and usually only confirmed after post-mortem) can a primary biological defect be identified as a cause of anorexia nervosa.

One attractive biological candidate for explaining many of the behavioural and psychological consequences of eating disorders is serotonin. Research indicates that anorexia nervosa is associated with increased serotonergic functioning and bulimia nervosa with reduced serotonergic functioning (Jimerson et al. 1992). This neurotransmitter is especially interesting as it is associated with the control of appetite, impulse control and depression. Furthermore, serotonin function is influenced by dieting. Women consuming $4.2 \mathrm{MJ} / \mathrm{d}$ have been found to have reduced levels of plasma tryptophan (the amino acid precursor of serotonin) and an altered serotonergic response (Anderson et al. 1990). What is more, this effect of dieting occurs in women but not in men. Not only are women more at risk of eating disorders because of the cultural pressures to be thin, but perhaps they are also biologically at risk as a result of this change in neurochemical responsiveness. Dieting appears to be the key which unlocks this important biological consequence.

Turning to the psychological consequences of dieting, a range of similarities are apparent in the behaviour, emotional, cognitive and perceptual state of normal dieters and individuals with an eating disorder. Research into dietary restraint has taken dieting into the laboratory for close experimental scrutiny in order to examine the effects of dieting on eating behaviour. What has been found is that dieters' restraint over their food intake is fragile in a variety of circumstances, provoking them to overconsume (Herman \& Polivy, 1980). The basic scenario is as follows. Subjects take part in an experiment which is ostensibly an investigation of taste perception. They are asked to evaluate the taste of ice-cream in the absence of, or following, a milkshake of a particular flavour. Participants are invited to eat freely from the bowls of ice-cream while making their judgements in absolute privacy. At the end of the experiment they complete a questionnaire on their dieting behaviour and the amount of ice-cream consumed is measured. The non-dieters were found to behave in a predictable fashion. They ate less ice-cream following one milkshake than after no milkshake, and still less following two milkshakes. In contrast, the dieters, rather than regulating their eating and accommodating for what they had previously eaten, appeared to counter-regulate and eat more 
ice-cream after one or two milkshakes than after no milkshake. Consuming a tasty high-energy milkshake apparently caused them to abandon their dieting resolve.

Dieters' eating behaviour is sensitive to a variety of circumstances including their own perceptions of the energy density of the milkshake, consuming alcohol, and the behaviour of their co-eater. What impresses many people about the research is the ecological validity of this series of experiments. These carefully delineated effects correspond to the daily life experiences of many people fighting to keep their eating under control. Moreover, there is little need to seek biological mechanisms for this behaviour. Herman \& Polivy (1991) argue that deliberate conscious control supersedes the learned regulatory strategies founded on physiological feedback. Dieters decide how much, what and when they will eat, irrespective of their natural biological inclinations. It is the difficulty in sticking to a consciously set energy agenda that prompts self-perceived failure. Eating a high-energy milkshake breaks the diet in the eyes of many dieters, and the damage having been done, they yield to the temptation of the ice-cream. For many, therefore, bringing eating under strictly psychological control invites failure.

A useful insight into the predicament of dieters is a study of a group of women and men who consumed 5 and $6.3 \mathrm{MJ} / \mathrm{d}$ respectively for 2 weeks (Warren \& Cooper, 1988). Compared with their pre-dieting baseline, this group of normal weight dieters experienced important changes in their cognitive control of eating. They reported significant increases in their preoccupation with thoughts about food or eating, and increases in ratings of 'felt a strong urge to eat' and 'felt out of control of your eating'. Having to negotiate this strong upsurge in demand for food may be something for which people are ill-prepared and ill-equipped. It is easy to see how failure to control eating and dieting transgressions could generalize to a person's overall self-perception. 'If I can't control my eating, what hope have I of controlling other areas of my life?' This erosion of self-esteem is seen in another of the laboratory studies. In this case, it was only the dieters with low self-esteem who displayed counter-regulatory eating. (Polivy et al. 1988).

If the effects of dieting on eating control and self-esteem have straightforward associations with anorexia nervosa, then it might be thought that the cognitive and perceptual distortions characteristic of anorexia are more difficult to find in dieters. In fact this is not the case. In many ways dieters are an intermediary group between non-dieters and those suffering clinical eating disorders. Take, for example, some of the cognitive distortions found in patients with eating disorders (Fairburn \& Cooper, 1989). Some typical examples include:

I must be thin because to be thin is to be successful, attractive and happy;

I must avoid being fat because to be fat is to be a failure, unattractive and unhappy; self-indulgence is bad since it is a sign of weakness;

self-control is good because it is a sign of strength and discipline;

anything less than total success is utter failure.

Such beliefs and values are extreme forms of more widely held views, and ones which may be particularly close to the hearts of dieters. What characterizes anorexia nervosa is their strength, degree of personal significance and inflexibility.

Dieting and anorexia nervosa may also share effects on the way information is processed. In a modified version of the Stroop test, anorexics were found to be slower than a non-eating disordered group in responding to food-related words (Channon et al. 
1988). This selective processing of food-related information is also seen in stringent dieters. In other contexts, this sensitivity to individually relevant stimuli is characteristic of people with anxiety states and phobias, and has provided an important insight into these clinical conditions.

A further indication of changes in cognitive function comes from recent investigations of measures of cognitive performance. Subjects who were dieting at the time of the study and had lost at least $1 \mathrm{~kg}$ on their current diet performed less well on a series of tasks assessing information processing, immediate memory and simple reaction time (Rogers et al. 1992). These results are indicative of an impairment of cognitive performance consistent with an attentional deficit. While the cause of this impairment may be a direct consequence of nutritional restriction or be related to the psychological effort expended in adhering to the diet, it is clear that dieting is far from inconsequential for cognitive function.

\section{CONCLUSIONS}

There are many features common to dieting and anorexia, and those raised here represent a truncated sift through what is now an extraordinary body of information. But this is written at what may be considered a critical time. Moves to tackle obesity have now harnessed Government support. In conjunction with our societal attitudes to overweight, Government policy, the platform of the media, and the powerful machine of industry, are set to drive the war against overweight. The supportive arguments are compelling and yet poorly focused. If we accept that dieting is not a purely benign practice, and that some sectors of the population are particularly susceptible to its cause and effects, then we are left with some serious questions. For example, when, and for whom are the dangers of dieting greater than the penalties of overweight. At the moment there are clues, but no public consensus.

The influences of the dieting culture must not be underplayed in their involvement with eating disorders. A great deal of evidence suggests that the prevalence of eating disorders is in direct proportion to the prevalence of dieting behaviour in a given population (Hsu, 1989). Not only are they related in frequency, dieting and eating disorders are related in nature. Herman \& Polivy (1991) have written: 'The abnormal psychology of dieting is simply a template for the abnormal psychology of eating disorders. And the symptoms of eating disorders - alternating abstinence and bingeing, emotional volatility, magical and disoriented thinking, low self-esteem and the pervasive pursuit of slimness - are all writ small in everyday dieting.'

With such a close association, any increase in the popularity of dieting must be viewed with caution. Is the trade-off of reduced obesity but increased eating disorders acceptable or even morally justified? Are there ways of mitigating the impact of the anti-obesity crusade, particularly on adolescent and young women? Self-imposed undernutrition in the cause of an externally appointed ideal weight may be a high price to pay for too many people.

\section{REFERENCES}

Anderson, 1. M., Parry-Billings, M., Newsholme, E. A., Fairburn, C. G. \& Cowen, P. J. (1990). Dieting reduces plasma tryptophan and alters brain 5-HT function in women. Psychological Medicine 20, 785-791.

Channon, S., Hemsley, D. \& de Silva, P. (1988). Selective processing of food words in anorexia nervosa. British Journal of Clinical Psychology 27, 259-260. 
De Jong, W. \& Kleck, R. E. (1986). The social psychological effects of overweight. In Physical Appearance, Stigma and Social Behaviour. The Ontario Symposium, vol. 3 [C. P. Herman, M. P. Zanna and E. T. Higgins, editors]. Hillsdale, NJ: Erlbaum.

Fairburn, C. G. \& Cooper, P. J. (1984). The clinical features of bulimia nervosa. British Journal of Psychiatry 144, 238-246.

Fairburn, C. G. \& Cooper, P. J. (1989), Eating disorders. In Cognitive Behaviour Therapy for Psychiatric Problems. A Practical Guide [K. Hawton, P. M. Salkovskis, J. Kirk and D. M. Clark, editors), Oxford: Oxford University Press.

Garrow, J. (1991). Importance of obesity. British Medical Journal 303, 704-706.

Gregory, J., Foster, K., Tyler, H. \& Wiseman, M. (1990). The Dietary and Nutritional Survey of British Adults. London: H.M. Stationery Office.

Herman, C. P. \& Polivy, J. (1980). Restrained eating. In Obesity [A. J. Stunkard, editor]. Philadelphia: Saunders.

Herman, C. P. \& Polivy, J. (1991). Fat is a psychological issue. New Scientist 1795, 41-45.

Hill, A. J., Oliver, S. \& Rogers, P. J. (1992). Eating in the adult world: the rise of dieting in childhood and adolescence. British Journal of Clinical Psychology 31, 95-105.

Hsu, L. K. G. (1983). The aetiology of anorexia nervosa. Psychological Medicine 13, 231-238.

Hsu, L. K. G. (1989). The gender gap in eating disorders: why are the eating disorders more common among women? Clinical Psychology Review 9, 393-407.

Jimerson, D. C., Lesem, M. D., Kaye, W. H. \& Brewerton, T. D. (1992). Low serotonin and dopamine metabolite concentrations in cerebrospinal fluid from bulimic patients with frequent binge episodes. Archives of General Psychiatry 49, 132-138.

Levine, M. P. (1987). How Schools Can Help Combat Eating Disorders. Washington, DC: National Education Association.

Patton, G. C., Johnson-Sabine, E., Wood, K., Mann, A. H. \& Wakeling, A. (1990). Abnormal eating attitudes in London schoolgirls - a prospective epidemiological study: outcome at twelve month follow-up. Psychological Medicine 20, 383-394.

Pirke, K. M. \& Ploog, D. (1986). Psychobiology of anorexia nervosa. In Nutrition and the Brain, vol. 7, pp. 167-198 [R. J. Wurtman and J. J. Wurtman, editors]. New York: Raven Press.

Polivy, J., Heatherton, T. F. \& Herman, C. P. (1988). Self-esteem, restraint and eating behaviour. Journal of Abnormal Psychology 97, 354-356.

Prentice, A. W., Goldberg, G. R., Jebb, S. A., Black, A. E., Murgatroyd, P. R. \& Diaz, E. O. (1991). Physiological responses to slimming. Proceedings of the Nutrition Society 50, 441-458.

Rodin, J., Silberstein, L. R. \& Striegel-Moore, R. H. (1985). Women and weight: a normative discontent. Nebraska Symposium on Motivation 32, 267-307.

Rogers, P. J., Edwards, S., Green, M. W. \& Jas, P. (1992). Nutritional influences on mood and cognitive performance: the menstrual cycle, caffeine and dieting. Proceedings of the Nutrition Society 51, 343-351.

Wardle, J. \& Marsland, L. (1990). Adolescent concerns about weight and eating: a social-developmental perspective. Journal of Psychosomatic Research 34, 377-391.

Warren, C. \& Cooper, P. J. (1988). Psychological effects of dieting. British Journal of Clinical Psychology 27, 269-270. 